\section{Cognitive aspects of reading}

The Psychology of Reading. By Eleanor

J. Gibson and Harry Levin. Pp. xii+ 630. (MIT: Reading, Massachusetts and London, 1975.) \$18.95.

THE republication of Huey's Psychology and Pedagogy of Reading after sixty years of general reticence on the topic has been accompanied by a rush of modern treatments. This rebirth of interest in reading reflects not only the cunning propensity of psychology for crop rotation but also an increasing interest of cognitive psychologists in skilled and intelligent performance. At the same time social concern about literacy, especially in the US, has enabled the psychologist, like a modern Danaë, to be possessed by Zeus in a shower of research funds. This volume by Gibson and Levin presents the most comprehensive engagement to date of cognitive psychology with the problem of reading.

The book consists of three sections, the first of which reviews the basic psychological and linguistic principles which the authors believe relevant. These include perceptual learning, work on general, cognitive and especially language development, basic linguistics and some specialised material on writing systems, and finally, a discussion of the considerable literature on the visual perception of words.

It is this extensive review section which sets the book apart and, in a sense, exhibits its academic credentials. The result is not entirely satisfactory. One problem is that the survey has scmething of the texture of 'annual review' articles, dense and impressively referenced but somehow lacking in coherence. The mass of data is insufficiently organised to be readily digested by the non-psychologist or to provide new insight for the specialist. Significantly, the introductory chapters on linguistics and writing systems are much more readable than those reviewing areas of experimental psychology. There are some obscurities, such as the curious description of Spoehr and Smith's research on pages 91-92 and the seemingly contradictory claims about the effect of orthographic regularity on letter search. But on the whole the text is dry and lucid.

The treatment of underlying concepts is lengthy yet some judgements have been made about exclusion of material. Notable absences include vision research such as metacontrast, much of the post-Sperling work on letter array processing and the important work of Meyer on lexical deci- sions. There is also little explicit treatment of general problems of pattern recognition.

The core of the book is the section on the reading process itself. This is rather more readable, not least because the view of basic questions is less obscured by an untidy forest of experimental data. This section should also prove fruitful to the non-specialist. It concludes with a review of models of skilled reading, which brings the discussion back to the preoccupations of experimental psychology. Here, in an attempt to invent some substantive issues the authors create a curious opposiion of 'information processing' and 'analysis-by-synthesis' models. This chapter also contains one of the occassional lapses into slightly partial reviewing, where (page 467) the claims of Gibson and her colleagues about an absence of acoustic or semantic effects on visual search are presented without

\section{Life gaining ground}

Surtsey: Evolution of Life on a Volcanic Island. By Sturla Fridriksson. Pp. 198. (Butterworth: London, 1975.) $£ 5.00$.

ON November 14, 1963, a submarine volcanic eruption began in the ocean south of the Westman Islands off the coast of Iceland, which eventually resulted in the production of an island with an area of 2.5 square kilometres. The island was aptly named Surtsey, after the mythical Norse fire-giant, Surtur the Black. The geological significance of this rare event was immediately apparent, but the biological opportunities presented by the occurrence are of no lesser importance. These were fortunately recognised by men such as Sturla Fridriksson, who visited the island within six months of its formation and began the formidable task of documenting the establishment of living organisms.

The succession of life on totally bare areas of land surface has not been bu studied intensively, mainly because of seeds in their gizzards, which could the lack of opportunity, especially in potentially provide an invasion mechanisolated situations where invasion de- ism.

mands very effective dispersal on the Finally, the developing biota of part of the organism concerned. Surtsey is compared with neighbouring Students must surely be weary of the islands and the mainland of Iceland, much repeated but rather fragmentary and naturally these seem to provide the information available from Krakatoa major source areas for invaders.

following its eruption in 1883. But in The book is well illustrated with this new book, Fridriksson has sum- some spectacular colour photographs marised the development of living com- as well as a large number of line drawmunities of organisms and simple eco- ings and maps. It is written in a lively, systems in the 10 years since the forma- informal manner, which effectively tion of Surtsey.

The study is extensive. It documents enthusiastic concern to observe the ecothe establishment of microbial life logical development of a truly pristine within months of the initial eruption, habitat.
P. D. Moore 